\title{
Different Perceptions of Parents and Children on Factors Influencing Sport Specialization
}

\author{
Mayrena I. Hernandez, Kevin M. Biese, Dan A. Schaefer, Eric G. Post, \\ David R. Bell, and M. Alison Brooks
}

\begin{abstract}
Context: Sport specialization among youth athletes has been associated with increased risk of overuse injuries. Previous research demonstrates that children perceive specialization to be beneficial in making their high school team and receiving athletic college scholarships. Previous research demonstrates that parents play a significant role in their child's sport experience. However, it is unknown if parents and children answer questions related to specialization factors in a similar manner. Objective: To evaluate the beliefs of youth athletes and parents on factors related to sport specialization and evaluate the level of agreement between dyads on sports specialization. Design: Cross-sectional. Setting: Online and paper surveys. Patients or Other Participants: Aim 1: 1998 participants (993 children and 1005 parents). Aim 2: 77 paired parent-child dyads. Interventions: Self-administered survey. Main Outcome Measures: The responses were summarized via frequency and proportions (\%). Chi-squares were calculated between parent and child responses. Kappa coefficients were calculated for dyads to determine level of agreement. Sport specialization was classified using a common 3-point scale. Results: The parents were more concerned about risk of injury in sports compared with children $\left(P<.001, \chi^{2}=231.4\right.$; parent: extremely: $7.1 \%$; child: extremely: $\left.3.7 \%\right)$. However, children were more likely to believe that specialization was associated with their chances of obtaining an athletic college scholarship compared with parents $\left(P<.001, \chi^{2}=201.6\right.$; parent: very/extremely likely: $13.7 \%$; child: very/extremely likely: $\left.15.8 \%\right)$. Dyad subanalysis indicated a moderate level of agreement for "quitting other sports to focus on one sport" $(\kappa=.50)$ and a low level of agreement for "identifying a primary sport" $(\kappa=.30)$ and "training $>8$ months per year in primary sport" $(\kappa=.32)$. Conclusions: Parents and youth athletes had differing beliefs on the factors related to sport specialization. Dyad analysis shows that parents and children answer sport specialization classification questions differently. Health care providers should be aware of these differences, and messaging should be individualized to the audience.
\end{abstract}

Keywords: youth athletes, pediatrics, injury prevention, musculoskeletal, club

It is estimated that 60 million adolescents in the United States participate in organized youth sports. ${ }^{1}$ Youth sport participation is often promoted and introduced early in life as a way for children to maintain a healthy lifestyle later in life and have social interactions, and as a means to have fun. ${ }^{2}$ Additionally, it provides an overall improved quality of life with a reduction in morbidity and mortality in adolescence and adulthood. ${ }^{3}$ Despite the positive attributes of organized sport, the emphasis on winning, maximizing sport performance, and obtaining athletic performance college scholarships have all led to increasing deliberate practice and competition in youth athletics. This trend has been coined sport specialization. ${ }^{4-8}$

Sport specialization is commonly defined as year-round participation in a single sport with intense, high-volume training. ${ }^{9}$ The consequences of sport specialization include overuse injuries and burnout. ${ }^{1,4,6,8-12}$ These consequences have prompted various medical organizations to release position statements warning against sport specialization, as well as recommending the need for more research on the limited data supporting these recommendations. ${ }^{1,7}$ These recommendations include time-based measurements for sport participation-such as months per year and hours per week, as well as avoiding participating in multiple leagues at the same time- to provide guidelines for youth athletes in organized sport to help prevent overuse injury.7,13,14 Two particular

Hernandez, Biese, Schaefer, Bell, and Brooks are with the University of WisconsinMadison, Madison, WI, USA. Post is with the San Diego State University, San Diego, CA, USA. Hernandez (mihernandez@wisc.edu) is corresponding author. recommendations state that children should not play one organized sport more than 8 months per year nor more hours per week than their chronological age ${ }^{15}$ meaning that a child who is 13 years of age should not participate in more than 13 hours of organized sport per week and should have at least 4 months off from sport. ${ }^{13}$

Previous research has investigated the attitudes and beliefs of youth club sport athletes and parents on sport specialization recommendations but has never directly compared these responses. ${ }^{16,17}$ Few studies exist comparing the attitudes and beliefs of children and their parents. The studies that do exist examined children and parent behaviors and beliefs on anxiety, eating disorders, and the perceptions of in-patient care. ${ }^{13,18,19}$ These studies demonstrated differences in the level of agreement and perceptions of treatment and care. ${ }^{13,18,19}$ If these differences exist in other health care fields, it is possible that a similar dichotomy of responses exists with sport specialization. Knowing how children and parents differ in their responses may help target interventions focused on safe sport participation for specific groups. The results of this study may lead to a better understanding of the attitudes of sport stakeholders that define the culture and subsequent behaviors of youth athletes in regard to sport specialization. The inclusion of multiple sport stakeholders in this study could provide a unique contribution to sport specialization research. It is also imperative that rehabilitation professionals be aware of the attitudes and beliefs of children and parents to better facilitate the rehabilitation process with their youth athlete patients and prevent sport specialization trends that lead to overuse injuries. Therefore, the purpose of this study was to compare the beliefs of youth athletes and parents 
on the factors related to sport specialization. A secondary purpose was to compare the level of agreement between parent and youth athlete dyads on sport specialization classification system questions. We hypothesized that children and parents will differ in their beliefs related to sport specialization. Additionally, we hypothesized that children and parent dyads will also differ in their beliefs related to the sport specialization classification system. This manuscript is a secondary analysis of previously published data, but with a different set of research questions.3,5 Additionally, the parent-child dyad information is also novel.

\section{Methods}

\section{Design}

This study is a cross-sectional descriptive survey of youth athletes and parents of youth athletes, as well as related parent-child dyads. Recruitment occurred at noninterscholastic club team events, such as tournaments, competitions, and practices at various local venues in the state of Wisconsin.

\section{Participants}

This study was approved by the institutional review board at The University of Wisconsin-Madison. To be eligible, youth athletes had to be between 12 and 18 years old and active in organized sports during the previous 12 months. The questionnaire was anonymous, and parents and athletes were provided with an information sheet that described the study before they provided oral consent to participate in the study.

\section{Procedures}

The questionnaires were completed by children, parents, and groups of parent-child dyads together on site at the tournament, competition, or practice and took approximately 15 minutes to complete. All questionnaires were oriented for the child's sport participation. The survey was divided into 4 sections and included (1) demographics (age, gender, and socioeconomic status) and information regarding all sports participation, (2) sport specialization status, (3) attitudes and beliefs regarding sport specialization and youth sport participation, and (4) injury history in the previous 12 months (which is neither discussed nor analyzed for the purpose of this article but was collected for both of the separate studies that this data set was originally intended for). The questionnaire sections were decided upon before the development of the study by a panel of experts ( 4 athletic trainers and 2 physicians with specialties in pediatric sports medicine).

Currently, a widely used 3-point sport specialization classification system exists to better classify (low, moderate, and high) youth athletes to help quantify and evaluate the risk factors outlined in these recommendations. ${ }^{9}, 10,16,17$ This classification system has been used to identify an association between highly specialized youth athletes and overuse injuries. The athletes were categorized in the 3-point specialization classification system as either lowly, moderately, or highly specialized, dependent upon their answers or the parents' answers about their child. A score is calculated from the following questions: (1) Have you quit other sports to focus on one sport? (2) Can you identify a primary sport? and (3) Do you train or participate in your primary sport more than 8 months out of the year? The responses were summed (yes $=1$, no $=0$ ), with a score of 3 classified as highly specialized, a score of 2 being moderately specialized, and a score of 0 or 1 considered lowly specialized.
Questions regarding the third section were developed using a panel of 4 athletic trainers and 2 physicians with specialties in pediatric sports medicine. This section included (1) attitudes toward injuries, (2) beliefs on the potential benefits and consequences of sport specialization, and (3) attitudes toward the importance of or various factors in deciding to participate in sports (eg, having fun, winning, spending time with friends, being physically active). The questions in this section were judged for the face, content validity, and ranked on a 5-point Likert scale ("not at all," "a little," "somewhat," "very," and "extremely"). The last question in this section asked the participants to rank their belief that they or their child would receive a college scholarship related to athletic performance on a 7-point Likert scale ("extremely unlikely," "very unlikely," "somewhat unlikely," "neither likely nor unlikely," "somewhat likely," "very likely," and "extremely likely"). Based on the survey development, the panel recommended to expand the college scholarship and athletic performance questions to provide the respondents with more options. These options were recommended given the rarity of the likelihood that the children will go on to receive a scholarship related to athletic performance.

Additional sections to this questionnaire included yes/no item responses to training time regarding primary sport, missing time with friends in order to participate in a primary sport, and quitting other sports to play in a primary sport. Last, a section on the number of months (selecting all that apply) and number of hours per week was asked regarding primary sport and organized sport (open answer).

\section{Statistical Analysis}

The responses were summarized by frequencies and proportions (\%) and means and SDs. Chi-square tests were used to compare the frequencies of whether or not the parents believed their child or children believed they would obtain a college scholarship between low, moderate, and high specialization athletes. A majority of the results were framed in terms of the response percentages of each group that rated items as "very" or "extremely" important. This was done to isolate more elite-striving parents/children. These rating proportions were used to compare children and parents. For the ease of graphic presentation, the 7-point Likert scale questions were collapsed into 3 categories by amount: 1 to 2 (a few), 3 to 5 (some), and 6 to 7 (most). Parents and children were analyzed independently in their ratings of these items. As a consequence of this expansion of the scale, it results in a violation of the assumptions of the chi-square, which were collapsed for analysis.

Kappa coefficients were calculated between dyads to determine the level of agreement for each sport specialization scale question. All statistical tests were 2-sided, with the statistical significance set a priori at $P<.05$. All analyses were performed using SPSS statistical software (version 22.0; IBM Corp, Armonk, NY).

\section{Results}

The surveys were distributed to 1005 parents and 1000 youth athletes. A total of 1998 participants (993 children, age = 14.1 [1.6] y and 1005 parents, age $=44.88$ [6.2] y) fully completed the questionnaire and were included in the analysis. During the data collection process, 77 paired parent-child dyads were identified and included for analysis. Approximately 39.1\% $(n=388)$ of the children self-classified as highly specialized, whereas $19.9 \%(\mathrm{n}=$ 202) of the parents reported on their child's specialization level as high. The 3 sports with the highest number of responses for the 
Table 1 Participant Demographics

\begin{tabular}{lcccc}
\hline & \multicolumn{4}{c}{ Dyads } \\
\cline { 2 - 5 } & Child & Parent & Child & Parent \\
\hline Sport specialization status & & & \\
Low & $255(25.7)$ & $431(42.4)$ & $21(27.3)$ & $27(35.1)$ \\
Moderate & $350(35.2)$ & $343(33.7)$ & $32(41.6)$ & $27(35.1)$ \\
High & $388(39.1)$ & $202(19.9)$ & $24(31.2)$ & $23(29.9)$ \\
Missing & 0 & $41(0.4)$ & 0 & 0 \\
Primary sport & & & & \\
Baseball/softball & $70(7)$ & $102(10)$ & & \\
Basketball & $315(31.7)$ & $343(33.7)$ & & \\
Cheer/dance & $9(0.9)$ & $8(0.8)$ & & \\
Cross-country & $6(0.6)$ & $16(1.6)$ & & \\
Football & $41(4.1)$ & $30(2.9)$ & & \\
Gymnastics & $2(0.2)$ & $5(0.5)$ & & \\
Ice Hockey & $66(6.6)$ & $74(7.3)$ & & \\
Lacrosse & $4(0.4)$ & $3(0.3)$ & & \\
Soccer & $141(14.2)$ & $227(22.3)$ & & \\
Softball & $24(2.4)$ & $58(5.7)$ & \\
Swimming & $12(1.2)$ & $13(1.3)$ & \\
Tennis & $3(0.3)$ & $1(0.1)$ & \\
Track & $1291.2)$ & $4(0.4)$ & \\
Volleyball & $279(28.1)$ & $165(16.2)$ & \\
Wrestling & $17(1.7)$ & $7(0.7)$ & & \\
Missing & $16(1.6)$ & $2(0.2)$ & & \\
\hline
\end{tabular}

aPlaying multiple sports equally and was unable to identify a "primary sport." children and parents, respectively, were basketball $(31.7 \%, \mathrm{n}=315$ and $33.7 \%, \mathrm{n}=343)$, volleyball $(28.1 \%, \mathrm{n}=279$ and $16.2 \%$, $\mathrm{n}=165)$, and soccer $(14.2 \%, \mathrm{n}=141$ and $22.3 \%, \mathrm{n}=227)$ (Table 1$)$. As for the paired parent-child dyad subgroup, 31.2\% ( $=24)$ of the children were self-classified as highly specialized, whereas $29.9 \%(n=23)$ of the parents classified their child as highly specialized (Table 1).

The parents were more concerned about risk of injury in sports compared with children $\left(P<.001, \chi^{2}=231.4\right.$; Figure 1$)$. However, the children were more likely to believe that specialization was associated with receiving a college scholarship $(P<.001$, $\chi^{2}=201.6$; Figure 2). When asked how many youth athletes receive college athletic scholarships, $93.8 \%$ of the parents believed that "a few" or "some of them" receive scholarships compared with the children's response of $85.6 \%\left(P<.00, \chi^{2}=185.6\right.$; Figure 3$)$.

The 3 factors that the children found the most important, being ranked as either "very" or "extremely" important, in their sport participation were the opportunity to get better at their sport $(95.8 \%, \mathrm{n}=937)$, being physically active $(89.8 \%, \mathrm{n}=874)$, and having fun $(88.6 \%, \mathrm{n}=864)$ (Table 2). The 3 factors that the parents found the most important in their child's sport participation, being ranked as either "very" or "extremely" important, were having fun $(92 \%, \mathrm{n}=909)$, the opportunity to get better $(82.5 \%$, $\mathrm{n}=817)$, and spending time with friends $(80.2 \%, \mathrm{n}=797)$ (Table 3). The 3 least important factors for the children, ranked as either "very" or "extremely" important, were increasing their chances of receiving a college scholarship $(67 \%, \mathrm{n}=676)$, winning $(67 \%, \mathrm{n}=658)$, and spending time with friends $(62 \%, \mathrm{n}=604)$, whereas for the parents, the least important factors, "very" or "extremely" important, were winning $(41.9 \%, n=417)$, increasing their child's ability to play on a travel, all-star, or elite team $(36.6 \%$, $\mathrm{n}=363$ ), and increasing their child's chances of receiving a college scholarship $(26.2 \%, \mathrm{n}=261)$.

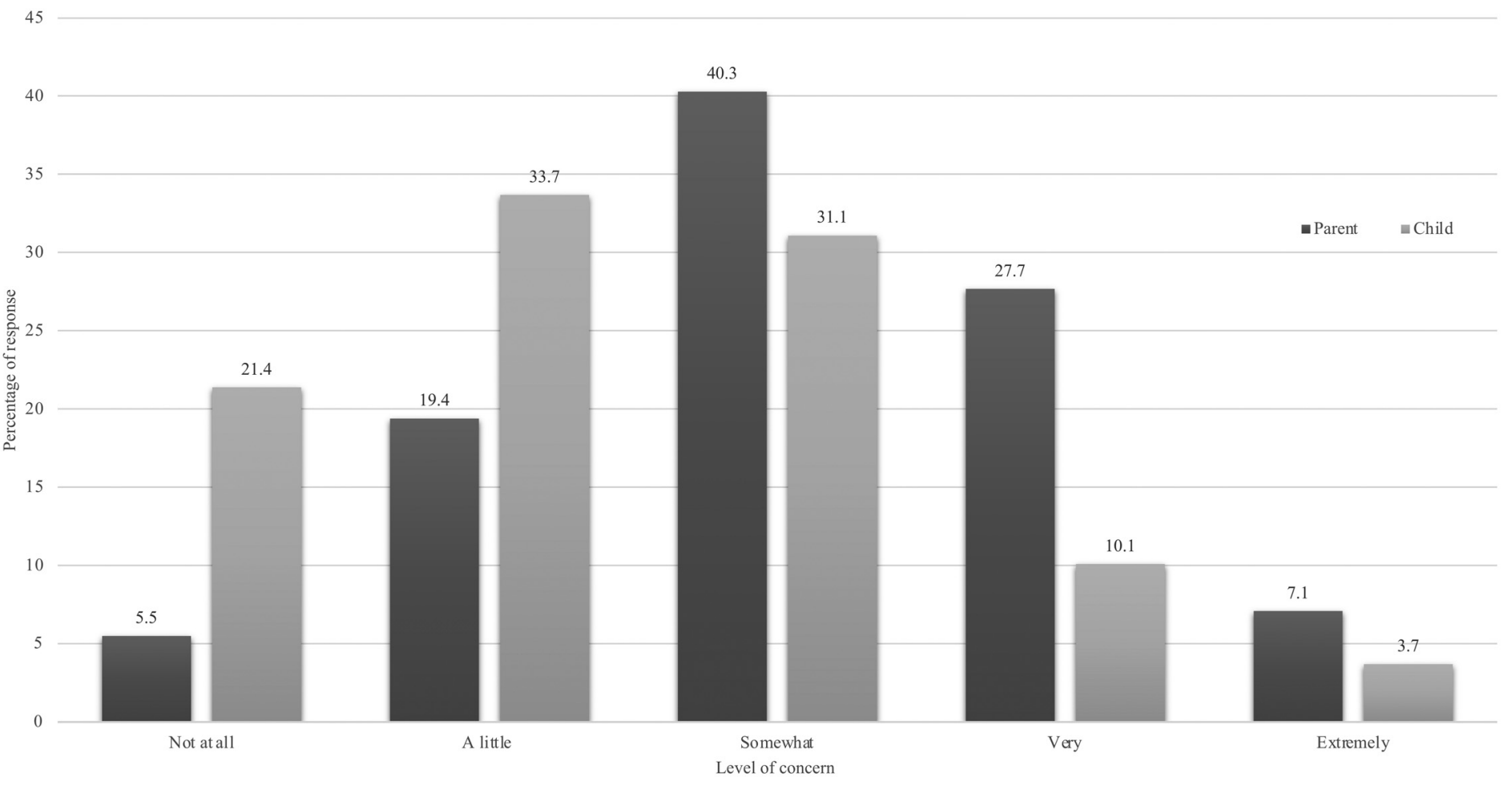

Figure 1 - Participant responses to the following question: "How concerned are you about (your child) getting injured while playing sports?" 


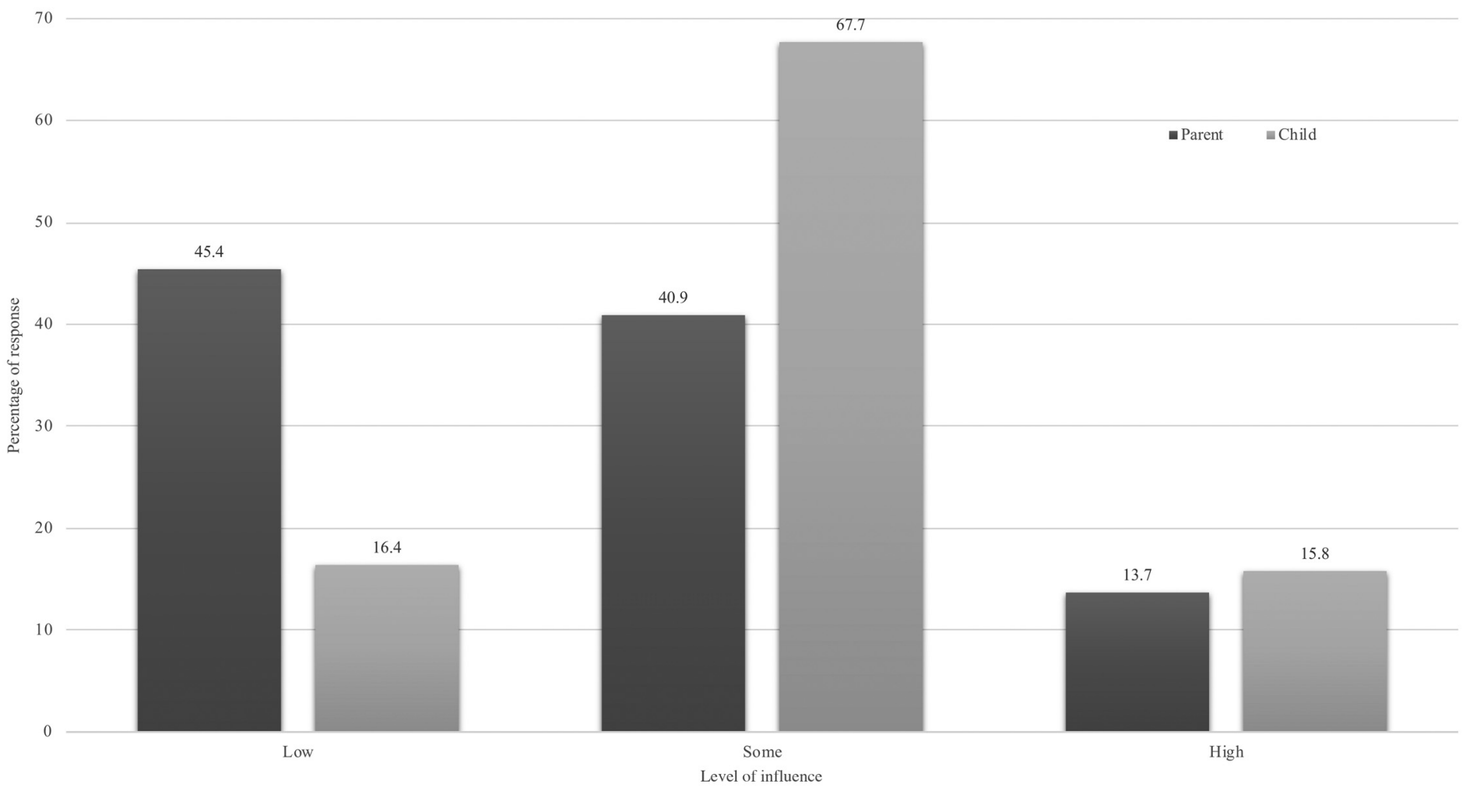

Figure 2 - Participant responses to the following question: "How likely do you believe it is that you (or your child) will receive a college scholarship that is related to athletic performance?"

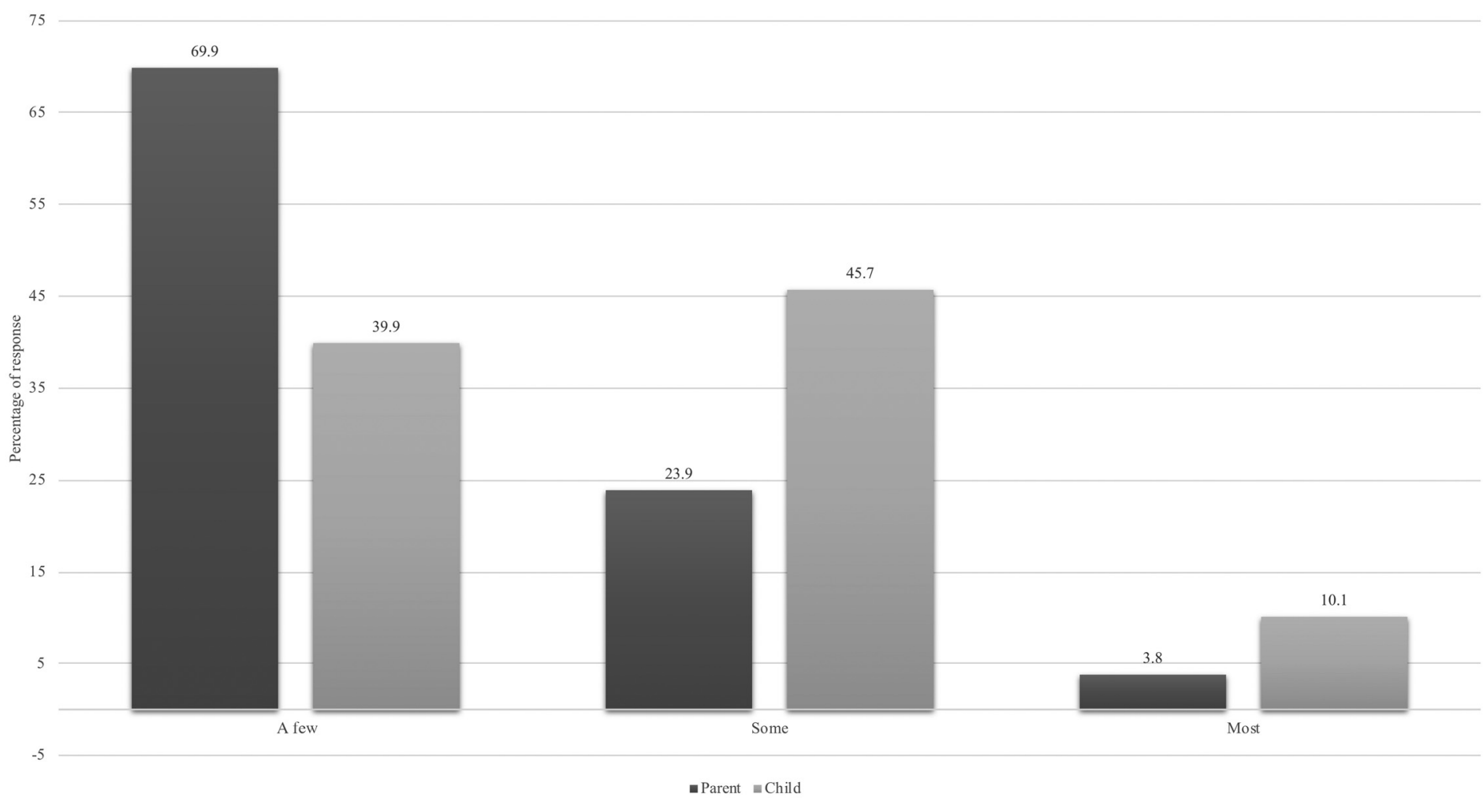

Figure 3 - Participant responses to the following question: "About how many youth athletes do you think receive a college scholarship that is related to athletic performance?" 
Table 2 Children Responses to Questions Regarding the Importance of Various Factors Affecting Their Decision to Participate in Youth Sports

\begin{tabular}{|c|c|c|c|c|c|}
\hline & Not at all & A little & Somewhat & Very & Extremely \\
\hline \multicolumn{6}{|l|}{ How important are the following parts of sports to you? } \\
\hline Winning & $14(1.4)$ & $66(6.7)$ & $244(24.8)$ & $378(38.5)$ & $280(28.5)$ \\
\hline Spending time with friends & $20(2.1)$ & $101(10.4)$ & $249(25.6)$ & $366(37.6)$ & $238(24.4)$ \\
\hline Developing life skills such as teamwork and friendship & $10(1)$ & $48(4.9)$ & $121(12.4)$ & $379(38.8)$ & $419(42.9)$ \\
\hline Having fun & $7(0.7)$ & $17(1.7)$ & $88(9)$ & $272(27.9)$ & $592(60.7)$ \\
\hline Increasing ability to make high school varsity teams & $21(2.1)$ & $29(3)$ & $120(12.3)$ & $303(30.9)$ & $506(51.7)$ \\
\hline Getting better at your sport & $3(0.3)$ & $5(0.5)$ & $33(3.4)$ & $243(24.8)$ & $694(71)$ \\
\hline Being physically active & $14(1.4)$ & $129(1.2)$ & $73(7.5)$ & $291(29.9)$ & $583(59.9)$ \\
\hline Increasing ability to play on a travel, all-star, or elite team & $42(4.3)$ & $57(5.9)$ & $163(16.8)$ & $314(32.3)$ & $397(40.8)$ \\
\hline Increasing chances of receiving a college scholarship & $75(7.6)$ & $81(8.3)$ & $167(17)$ & $223(22.7)$ & $435(44.3)$ \\
\hline
\end{tabular}

Data are expressed as $\mathrm{n}(\%)$.

Table 3 Parent Responses to Questions Regarding the Importance of Various Factors Affecting Their Decision to Participate in Youth Sports

\begin{tabular}{|c|c|c|c|c|c|}
\hline & Not at all & A little & Somewhat & Very & Extremely \\
\hline \multicolumn{6}{|l|}{ How important are the following parts of sports to you? } \\
\hline Winning & $17(1.7)$ & $109(11)$ & $451(45.4)$ & $351(35.3)$ & $66(6.6)$ \\
\hline Spending time with friends & $4(0.4)$ & $36(3.6)$ & $157(15.8)$ & $541(54.4)$ & $256(25.8)$ \\
\hline Developing life skills such as teamwork and friendship & $13(1.3)$ & $69(7)$ & $231(23.3)$ & $437(44.1)$ & $242(24.4)$ \\
\hline Having fun & $1(0.1)$ & $9(0.9)$ & $69(7)$ & $469(47.5)$ & $440(44.5)$ \\
\hline Increasing ability to make high school varsity teams & $56(5.7)$ & $95(9.6)$ & $265(26.8)$ & $362(36.6)$ & $211(21.3)$ \\
\hline Getting better at your sport & $1(0.1)$ & $17(1.7)$ & $156(15.7)$ & $509(51.4)$ & $308(31.1)$ \\
\hline Being physically active & $15(1.5)$ & $61(6.3)$ & $218(22.4)$ & $414(42.5)$ & $267(27.4)$ \\
\hline Increasing ability to play on a travel, all-star, or elite team & $128(12.9)$ & $179(18)$ & $322(32.5)$ & $251(25.3)$ & $112(11.3)$ \\
\hline Increasing chances of receiving a college scholarship & $306(30.9)$ & $207(20.9)$ & $217(21.9)$ & $157(15.8)$ & $104(10.5)$ \\
\hline
\end{tabular}

Data are expressed as $\mathrm{n}(\%)$.

The most important factors for sport participation were significantly different between the children and parents. The children were more likely than the parents to rate the following factors as "very" or "extremely" important: winning $\left(67 \%\right.$ vs $42 \%, \chi^{2}=126.09, P<$ $.001)$; life skills $\left(81.7 \%\right.$ vs $\left.68.4 \%, \chi^{2}=46.46, P<.001\right)$; making a varsity team $\left(82.6 \%\right.$ vs $\left.57.9 \%, \chi^{2}=143.63, P<.001\right)$; getting better at sport $\left(95.8 \%\right.$ vs $\left.82.4 \%, \chi^{2}=95.5, P<.001\right)$; being physically active $\left(89.8 \%\right.$ vs $\left.69.8 \%, \chi^{2}=127.38, P<.001\right)$; ability to make a travel team $\left(73.1 \%\right.$ vs $\left.36.6 \%, \chi^{2}=265.623, P<.001\right)$; and obtain an athletic scholarship $\left(67.1 \%\right.$ vs $\left.26.3 \%, \chi^{2}=357.6, P<.001\right)$. Conversely, the parents were slightly more likely than the children to rate the following factors as "very" or "extremely" important: time with friends $\left(80.2 \%\right.$ vs $\left.62 \%, \chi^{2}=82.45, P<.001\right)$ and having fun (92\% vs $\left.88.5 \%, \chi^{2}=9.53, P<.01\right)$.

The parents and children answered differently when asked the number of months dedicated to playing the child's primary sport (parents: 8.56 [3.00] mo vs children: 8.40 [3.45] mo, $P<.001$ ), total months of organized sport (parents: 10.47 [2.49] mo vs children: 10.14 [2.78] mo, $P<.001)$, hours per week dedicated to primary sport (parents: 11.86 [10.68] h vs children: 13.23 [9.90] h, $P<.001$ ), and hours per week dedicated to organized sport (parents: 13.11 [8.61] h vs children: 16.34 [12.22] h, $P<.001$ ).

Dyad subanalysis indicated a moderate level of agreement and $75 \%$ agreement between parents and children for quitting other sports to focus on one sport, and a low level of agreement and 56\% agreement for "primary sports to be more important than other sports," and "training $>8$ months per year in primary sport" (Table 4). Only $57 \%$ of the parents and children were classified into the same category using the 3-point classification system, even though they might have answered questions differently.

\section{Discussion}

The purpose of this study was to gain an understanding of the comparative differences between youth athletes and parents in a club sport setting on the factors related to sport specialization, with a secondary purpose of comparing the level of agreement between parent and youth athlete dyads on sport specialization classification system questions. The most important finding of this study is that

\section{Table 4 Parent-Child Dyad Level of Agreement}

\begin{tabular}{lll}
\hline & $\kappa$ & $\%$ Agreement \\
\hline Sport specialization scale questions & & \\
Quitting sport for primary sport & .5 & 75 \\
Primary sport more important & .3 & 56 \\
Training >8 mo/y in primary sport & .32 & 56 \\
\hline
\end{tabular}

Data are expressed as Cohen $\kappa$. 
parents and children have different attitudes and beliefs related to sport specialization. There was also a low level of agreement observed between linked parent-child dyads focusing on the 3 -point classification system questions. These findings seem to indicate that messaging about safe sport recommendations and sport specialization should be individualized to parents and children.

Approximately between $1 \%$ and $2 \%$ of high school athletes will receive an athletic scholarship. Parents seem to be more reasonable when assessing college scholarship potential based on athletic performance when compared with children. However, these numbers are still high, considering that most student-athletes who receive these athletic scholarships are only covering a portion of a full scholarship. ${ }^{20}$ Full scholarships typically will cover tuition and fees, room and board, and course-related books. For example, an National Collegiate Athletic Association Division I school can distribute the allotted 9.9 full scholarships for an average soccer roster of 28 to 29 athletes but with the caveat of limits on how many athletes out of the team can benefit from the distribution of scholarships. ${ }^{20,21}$ Previous studies have found that it is relatively uncommon for National Collegiate Athletic Association Division I athletes to have specialized early in high school to compete at a college level. ${ }^{22,23}$ In a retrospective study comparing current high school, college, and professional athletes, obtaining a college athletic scholarship was commonly mentioned as a driver for early sport participation and focus on a single sport when it came to factors that drive youth sport specialization. ${ }^{6}$ Unfortunately, the likelihood of competing at an elite level is small, with a reported $3.3 \%$ to $6.8 \%$ of high school athletes competing at the college level and an even smaller percentage at the professional level. ${ }^{21,24}$ The proportion of club sport athletes obtaining a college athletic scholarship may differ from those of interscholastic participation estimates alone because of their association with more professionalized, highly specialized patterns of sport participation. Further research should be conducted on the likelihood of receiving a college scholarship between athletes in the club versus interscholastic setting and their interaction with the specialization status.

Children were more likely to believe that specialization also improves their chances to play on a travel, all-star, elite, or high school varsity team. Similar findings highlight that, for children, increased competition and pressure from parents, coaches, and peers at younger ages and lower levels of play, have become more prevalent reasons to specialize and compete year-round, to keep up with peers in their sport. ${ }^{11,17,25}$ Coaches are the primary reason children decide to participate in high-volume activity. ${ }^{25,26}$ Recent findings demonstrate that, specifically, club coaches' perceptions of sport specialization differ from high school coaches', with club coaches more likely to rate specialization as a positive. ${ }^{26}$ It is logical to assume that part of the reason children decide to specialize is that club coaches are asking them to do so. However, future research should investigate this more directly.

Parents are more concerned about the risk of injury in sports compared with children. Mothers are more concerned about injury when compared with fathers. ${ }^{16}$ This is consistent with previous literature focusing on concussions, in which parents are more concerned than children and mothers are more concerned than fathers about concussions. ${ }^{27}$ These results demonstrate that more work is needed to identify better ways of messaging the negative aspects of sport specialization to children and parents. ${ }^{1,8,22,28,29}$

The top 3 factors that children ranked as either "very" or "extremely" important in their sport participation were the opportunity to get better at their sport, physical activity, and having fun. This was not surprising, as it aligns with previous research, ranking "having fun" as the primary reason that children participate in sports. ${ }^{2}$ The primary determinants of whether sport participation is fun for youth athletes are learning and improving at a sport. ${ }^{2}$ Children identified that they did not participate in sports to spend time with friends. This may be attributed to most of the children subjects participating in a club team. It is also possible that most of these children's friends played on the same club team; therefore participating in sports is equivalent to social time with friends. However, $82 \%$ of our children cohort answered "yes" when asked if they had missed time with their friends in the past year because of sport participation. This may demonstrate that this set of children cohort see their athletic goals as more important than recreational time with their friends. ${ }^{17}$ The top 3 factors for sport participation for parents were having fun, the opportunity to get better at their sport, and spending time with friends. The differences between the children and parents demonstrate the need for individualized messaging to target these top factors to better inform these groups about the potential risks of sport specialization.

For the dyad analysis, there was a moderate level of agreement between the parents and children when asked if they (their child) had quit other sports for a primary sport. There was a low level of agreement for the remainder of the sport specialization classification questions (identifying a primary sport and training over $8 \mathrm{mo} / \mathrm{y}$ ). The results of this dyad analysis agree with the parent-child dyad research across other health care professions, concluding that there are low levels of agreement between parents and children. ${ }^{30}$ This shows the need to have both parties involved when questioning or consistently using the same group, either parents or children, when it pertains to determining the specialization level of a youth athlete. ${ }^{16,17,30,31}$ Knowing the specialization level of an athlete can better equip clinicians to address sport specialization. Future research is encouraged to further understand the lack of agreement between parent-child and its impact on participation behaviors, performance outcomes, and psychosocial experiences.

\section{Limitations}

There are several limitations to this study. Athletes were recruited at sport tournaments and competitions within a single state in a cross-sectional manner; thus, our results potentially do not capture sport attitudes and beliefs that may differ in states of differing climates, cultures, or socioeconomic status. Similarly, the athletes and parents recruited were primarily club teams competing in sports events outside of the school setting, which potentially does not fully capture the attitudes and beliefs of all sport settings, including interscholastic sports. The perceptions of the factors related to sport specialization in interscholastic events may differ from those observed in this study. In addition, bias may be a concern if a parent was motivated to participate in the survey if they were concerned or interested in the topic. Last, the degree of specialization of the child was determined at one time point. The perceptions and beliefs of these children and parents could have differed over the course of development.

\section{Conclusion}

There are significant differences in the responses between parents and children when answering questions related to their sport participation in the club sport setting. With parents, there seems to be a larger concern of risk of injury and low belief of obtaining a college scholarship associated with specialization, possibly 
indicating that awareness of the sport specialization issue is increasing among parents. Unfortunately, the same cannot be said for children. The disagreement between parents and children indicates the need for improved communication and education regarding the risks and benefits of sport specialization between sport governing bodies, team, league organizers, parents, and children. Rehabilitation professionals are in an ideal position to increase awareness of these issues with all stakeholders, not just adults. The question still remains how to adequately address these different data sources from parents and children, underlining the need for validation studies.

\section{References}

1. DiFiori JP, Benjamin HJ, Brenner JS, et al. Overuse injuries and burnout in youth sports: a position statement from the American Medical Society for Sports Medicine. Br J Sports Med. 2014; 48:287-288. PubMed ID: 24463910 doi:10.1136/bjsports-2013093299

2. Visek AJ, Achrati SM, Mannix H, et al. The fun integration theory: toward sustaining children and adolescents sport participation. J Phys Act Health. 2015;12:424-433. PubMed ID: 24770788 doi:10.1123/ jpah.2013-0180

3. Bailey R. Physical education and sport in schools: a review of benefits and outcomes. J Sch Health. 2006;76:397-401. PubMed ID: 16978162 doi:10.1111/j.1746-1561.2006.00132.x

4. Bell DR, Post EG, Trigsted SM, et al. Prevalence of sport specialization in high school athletics: a 1-year observational study. Am J Sports Med. 2016;44:1469-1474. PubMed ID: 26920433 doi:10.1177/ 0363546516629943

5. Brenner JS, Council on Sports Medicine and Fitness. Sports specialization and intensive training in young athletes. Pediatrics. 2016; 138(3):pii: e20162148. doi:10.1542/peds.2016-2148

6. Buckley PS, Bishop M, Kane P, et al. Early single-sport specialization: a survey of 3090 high school, collegiate, and professional athletes. Orthop J Sports Med. 2017;5:2325967117703944. PubMed ID: 28812031

7. LaPrade RF, Agel J, Baker J, et al. AOSSM early sport specialization consensus statement. Orthop J Sports Med. 2016;4:232596711664424. PubMed ID: 27169132 doi:10.1177/2325967116644241

8. McGuine TA, Post EG, Hetzel SJ, et al. A prospective study on the effect of sport specialization on lower extremity injury rates in high school athletes. Am J Sports Med. 2017;45:2706-2712. PubMed ID: 28735552 doi:10.1177/0363546517710213

9. Jayanthi NA, LaBella CR, Fischer D, et al. Sports-specialized intensive training and the risk of injury in young athletes: a clinical casecontrol study. Am J Sports Med. 2015;43:794-801. PubMed ID: 25646361 doi:10.1177/0363546514567298

10. Post EG, Bell DR, Trigsted SM, et al. Association of competition volume, club sports, and sport specialization with sex and lower extremity injury history in high school athletes. Sports Health. 2017;9:518-523. PubMed ID: 28628419 doi:10.1177/ 1941738117714160

11. Post EG, Trigsted SM, Riekena JW, et al. The association of sport specialization and training volume with injury history in youth athletes. Am J Sports Med. 2017;45:1405-1412. PubMed ID: 28288281 doi:10.1177/0363546517690848

12. Hall R, Barber Foss K, Hewett TE, et al. Sport specialization's association with an increased risk of developing anterior knee pain in adolescent female athletes. J Sport Rehabil. 2015;24:31-35. PubMed ID: 24622506 doi:10.1123/jsr.2013-0101
13. Hellstedt J. Invisible players: a family systems model. Clin Sports Med. 2005;24:899-928, x. PubMed ID: 16169453 doi:10.1016/j.csm. 2005.06.001

14. Bergeron MF, Mountjoy M, Armstrong N, et al. International Olympic Committee consensus statement on youth athletic development. Br J Sports Med. 2015;49:843-851. PubMed ID: 26084524 doi:10. 1136/bjsports-2015-094962

15. Intensive training and sports specialization in young athletes. Pediatrics. 2000;106:154-157. PubMed ID: 10878168

16. Bell DR, Post EG, Trigsted SM, et al. Parents' awareness and perceptions of sport specialization and injury prevention recommendations [published online ahead of print August 8, 2018]. Clin J Sport Med. PubMed ID: 30095505 doi:10.1097/JSM.0000000000000648

17. Brooks MA, Post EG, Trigsted SM, et al. Knowledge, attitudes, and beliefs of youth club athletes toward sport specialization and sport participation. Orthop J Sports Med. 2018;6:232596711876983. PubMed ID: 29770341 doi:10.1177/2325967118769836

18. Briggs-Gowan MJ, Carter AS, Schwab-Stone M. Discrepancies among mother, child, and teacher reports: examining the contributions of maternal depression and anxiety. J Abnorm Child Psychol. 1996;24:749-765. PubMed ID: 8970908 doi:10.1007/ BF01664738

19. Storch EA, Ehrenreich May J, Wood JJ, et al. Multiple informant agreement on the anxiety disorders interview schedule in youth with autism spectrum disorders. J Child Adolesc Psychopharmacol. 2012;22:292-299. PubMed ID: 22856332 doi:10.1089/cap.2011.0114

20. Jcoleman@ncaa.org. Scholarships. NCAA.org_The Official Site of the NCAA. 2017. Available from http://www.ncaa.org/studentathletes/future/scholarships. Published March 10, 2017. Accessed April 3, 2020.

21. Thomas D. Probability of competing beyond high school. 2019. Available from http://www.ncaa.org/about/resources/research/ probability-competing-beyond-high-school.

22. Post EG, Thein-Nissenbaum JM, Stiffler MR, et al. High school sport specialization patterns of current division I athletes. Sports Health. 2017;9:148-153. PubMed ID: 27807260 doi:10.1177/ 1941738116675455

23. Swindell HW, Marcille ML, Trofa DP, et al. An analysis of sports specialization in NCAA division I collegiate athletics. Orthop $J$ Sports Med. 2019;7:232596711882117. PubMed ID: 30729145 doi:10.1177/2325967118821179

24. Bar-Or O. The young athlete: some physiological considerations. J Sports Sci. 1995;13:S31-S33. doi:10.1080/02640419508732274

25. Fraser-Thomas J, Côté J, Deakin J. Understanding dropout and prolonged engagement in adolescent competitive sport. Psychol Sport Exerc. 2008;9:645-662. doi:10.1016/j.psychsport.2007.08.003

26. DiSanti JS, Post EG, Bell DR, et al. Exploring coaches' perceptions of youth sport specialization: a comparison of high school and club sport contexts. J Athl Train. 2019;54:1055-1060. PubMed ID: 31633416 doi:10.4085/1062-6050-409-18

27. Bloodgood B, Inokuchi D, Shawver W, et al. Exploration of awareness, knowledge, and perceptions of traumatic brain injury among American youth athletes and their parents. J Adolesc Health. 2013;53:34-39. PubMed ID: 23583508 doi:10.1016/j.jadohealth.2013.01.022

28. Bridge MW, Toms MR. The specialising or sampling debate: a retrospective analysis of adolescent sports participation in the UK. J Sports Sci. 2013;31:87-96. PubMed ID: 22974248 doi:10.1080/ 02640414.2012.721560

29. Moesch K, Elbe A-M, Hauge M-LT, et al. Late specialization: the key to success in centimeters, grams, or seconds (cgs) sports. Scand J Med Sci Sports. 2011;21:e282-e290. PubMed ID: 21401722 doi:10.1111/ j.1600-0838.2010.01280.x 
30. Hargreaves DS, Sizmur S, Pitchforth J, et al. Children and young people's versus parents' responses in an English national inpatient survey. Arch Dis Child. 2018;103:486-491. PubMed ID: 29434020 doi:10.1136/archdischild-2017-313801
31. Hargreaves DS, Greaves F, Levay C, et al. Comparison of health care experience and access between young and older adults in 11 highincome countries. J Adolesc Health. 2015;57:413-420. doi:10.1016/ j.jadohealth.2015.05.015 